\title{
Benefits of Enterprise Ontology for the Development of ICT-Based Value Networks
}

\author{
Antonia Albani and Jan L.G. Dietz \\ Delft University of Technology \\ Chair of Information Systems Design \\ PO Box 5031, 2600 GA Delft, The Netherlands \\ \{a.albani,j.l.g.dietz\}@tudelft.nl
}

\begin{abstract}
The competitiveness of value networks is highly dependent on the cooperation between business partners and the interoperability of their information systems. Innovations in information and communication technology (ICT), primarily the emergence of the Internet, offer possibilities to increase the interoperability of information systems and therefore enable inter-enterprise cooperation. For the design of inter-enterprise information systems, the concept of business component appears to be very promising. However, the identification of business components is strongly dependent on the appropriateness and the quality of the underlying business domain model. The ontological model of an enterprise - or an enterprise network - as presented in this article, is a highquality and very adequate business domain model. It provides all essential information that is necessary for the design of the supporting information systems, and at a level of abstraction that makes it also understandable for business people. The application of enterprise ontology for the identification of business components is clarified. To exemplify our approach, a practical case is taken from the domain of strategic supply network development. By doing this, a widespread problem of the practical application of inter-enterprise information systems is being addressed.
\end{abstract}

\section{Introduction}

Driven by drastic changing market conditions companies are facing an increasingly complex competitive landscape. Decisive factors such as globalization of sales and sourcing markets, shortened product life cycles, innovative pressure on products, services and processes and customers' request for individual products are forcing companies to undergo a drastic transformation of business processes as well as organizational and managerial structures [1]. The shift from a function-oriented to a process-oriented organization with a strong customer focus is essential in order to better adapt to fast changing market requirements and to become more flexible while meeting individual customer demands. Within an enterprise the core business processes need to be identified, improved and (partly) automated, while at the same time other processes are outsourced to business partners [2, 3]. As a consequence, business processes concerning e.g. product development, market research, sales, production, 
delivery and services are affected and have to be adjusted and integrated not only within a single company but also over multiple tiers of suppliers. Corporate networks, so called value networks [4-6], are formed to better fulfill specific customer requests providing customized products on time in the right quality and at a competitive price. In order to enhance the competitive advantages of value networks, the selection, development, management and integration of respective suppliers, located not only in tier-1 but also in the subsequent tiers, is of great relevance for enabling effective cooperation between enterprises. Modern information and communication technologies (ICT) - like the Internet, semantic standards, distributed applications, component based and service-oriented architectures - are necessary in order to enable the creation and management of dynamic corporate networks [7]. However, the deployment of information and communication technologies for enabling interoperability between business partners does not always meet expectations. At present, ICT-enabled value networks can be largely found in the form of rather small, flexible alliances of professionalized participants. The support of large value networks with multiple tiers of suppliers still causes considerable difficulties. The high degree of complexity resulting from dynamic changes in value networks is the main reason for the lack of practical implementations [8].

Looking at the potential of enabling and improving inter-enterprise cooperation by applying ICT, this article contributes to that area by illustrating the benefits of enterprise ontology for the development of ICT-based value networks. For developing intra- and inter-enterprise information systems it is necessary to use a suitable methodology for modeling the business domain satisfying defined quality criteria and for eliciting the relevant business requirements. Additionally, information systems need to be modeled on a level of abstraction that is understood also by the business people, who are defining the requirements and using the respective systems. The application of business components [9] for the design of high-level information systems appears to be adequate since they directly implement the business activities in an enterprise [9]. All other components are considered either to deliver services to these business components or to offer some general functionality. The identification of business components thus is the first step in the development of an information system according to current standards (component-based, object-oriented, etc.). Needless to say that this step is a very crucial one and that it should be performed at the highest possible level of quality. In the area of business components identification the research initiatives are still scarce see [10-12]. Vitharana [13] recognized that more formal approaches are needed to make the component based paradigm into an effective development tool. The starting point is the set of requirements that have been elicited from the business domain. Requirements engineering is still a weak link, although considerable improvements can be achieved if it is based on an appropriate and highquality business domain model. Such a model offers a more objective starting point for extracting requirements and a more objective criterion for evaluating them than the traditional 'waiter strategy' [14]. In a very true sense however, this new approach to engineering requirements shifts the problem only to an earlier stage instead of solving it. The crucial factors now are the appropriateness and the quality of the business domain model. In [15] some quality criteria are proposed regarding a business domain model, which we adopted for our current research: 
- It should make a clear and well-founded distinction between the essential business and infological actions. For example, delivering services to customers is essential, but computing the price to be paid is infological (it doesn't produce a new fact).

- It should have the right granularity or level of detail. "Right" in this respect means: finding the actions that are atomic from the business point of view. They may be composite only in their implementations. For example, the request to a supplier is atomic from the business point of view, but to perform a request by postal mail, a number of other (non-essential) actions have to be taken like sending the order form, transporting it and delivering it to the supplier.

- It should be complete, i.e. it should contain everything that is necessary and it should not contain anything that is irrelevant. As will be shown in the following, this requirement is probably the hardest to satisfy since it is common practice in most organizations to perform several kinds of coordination acts tacitly, according to the rule "no news is good news".

We call a business domain model that satisfies these requirements an enterprise ontology. Several domain modeling techniques exist propagating the business specific aspect of enterprise modeling, but most of them do not satisfy the quality criteria just mentioned. Looking at business processes modeling techniques, being a relevant part of domain modeling, next to the traditional flow charts, there exist e.g. Petri Net [16, 17], Event Driven Process Chains (EPC) [18] and Activity Diagrams [19]. However, in these techniques the notion of business processes is not well defined and there exists no distinction between business and infological actions. Consequently the difference between business processes and other kinds of process remains unclear. This leads to the conclusion that they do not specifically address business processes but can be used for any discrete event process. Other approaches, as e.g. from the Language/Action Perspective (LAP), claim to offer a solution for the mismatch between social perspectives and technical perspectives by explicitly focusing on business specific communication patterns, where social beings achieve changes in the (object) world by means of communication acts [20]. The enterprise ontology [21, 22] methodology is an approach that incorporates LAP and that additionally distinguishes between essential (business), infological and datalogical acts and facts, ultimately resulting in the distinction between three aspect organizations: the B-organization (B from business), the I-organization (I from infological), and the D-organization (D from datalogical). The apparent advantages of enterprise ontology - in particular the huge reduction of complexity [23] - led us to choose this methodology for modeling the business domain.

This article builds on previous work regarding enterprise ontology [21, 22] and business components [24-26]. To exemplify the usability of the proposed enterprise ontology and the identification of business components the domain of strategic supply network development [27-29] is introduced as a practical application of interenterprise information systems. The domain extends the frame of reference in strategic sourcing from a supplier centric to a supply network perspective and addresses a widespread problem in the practical application of inter-enterprise information systems. It is structured as follows: in section 2 the domain of strategic supply network development (SSND) is introduced. SSND is used throughout the article as an example domain for inter-enterprise cooperation. In section 3 we present the method that is used to arrive at a right ontological model of an enterprise. To illustrate it, the 
ontology of the SSND case is developed. In section 4, the method for identifying business components is applied to the SSND case. Discussions of the results as well as the conclusions that can be drawn are provided in section 5 .

\section{The Domain of Strategic Supply Network Development}

The relevance of the purchasing function in enterprises has increased steadily over the past two decades. Till the 70's, purchasing was widely considered an operational task with no apparent influence on long term planning and strategy development [30]. This narrow perspective was broadened by research that documented the positive influence that a targeted supplier cooperation and qualification could bring to a company's strategic options [31]. In the 80's, trends spurred the recognition of the eminent importance of the development and management of supplier relationships for gaining competitive advantages. Such trends were e.g., the growing globalization, the focus on core competencies in the value chain with connected in-sourcing and out-sourcing decisions, as well as new concepts in manufacturing. As a result, purchasing gradually gained strategic relevance on top of its operational and tactical relevance [32].

Based on these developments, purchasing has become a core function in the 90's. Current empiric research shows a significant correlation between the establishment of a strategic purchasing function and the financial success of an enterprise, independent from the industry surveyed [33, p. 513]. One of the most important factors in this connection is the buyer-supplier-relationship. At many of the surveyed companies, a close cooperation between buyer and supplier led to process improvements and resulting cost reductions that were shared between buyer and suppliers [33, p. 516].

In practice, supplier development is widely limited to suppliers in tier-1, i.e. the direct suppliers. With respect to the superior importance of supplier development, as mentioned above, we postulated the extension of the traditional frame of reference in strategic sourcing from a supplier-centric to a supply-network scope [27-29]. It means the further development of the strategic supplier development to a strategic supply network development. This shifted the perspective in the field of strategic sourcing to analyze multi-tier supplier networks instead of single suppliers.

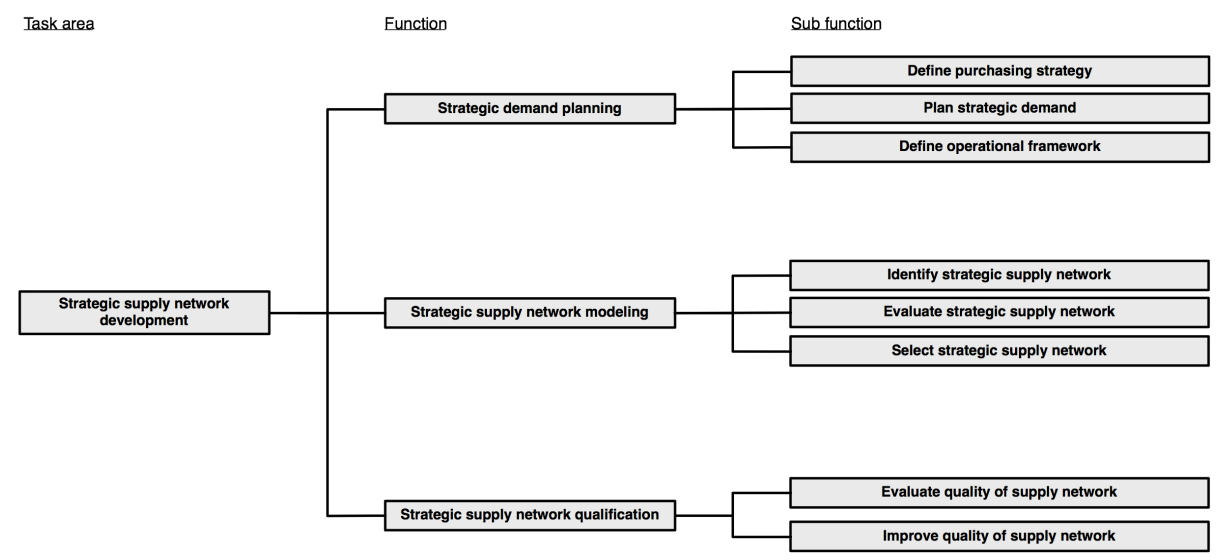

Fig. 1. Functional decomposition diagram for strategic supply network development 
The tasks within the strategic supply network development can be grouped into 3 main areas as illustrated in Fig. 1: strategic demand planning, strategic supply network modeling and strategic supply network qualification [34].

Within the function strategic demand planning, a corporate framework for all purchasing-related activities is defined. This framework consists of a consistent and corporate-wide valid purchasing strategy (define purchasing strategy), a strategic demand planning and demand bundling function (plan strategic demand), and the definition of methods and tools to control performance and efficiency of purchasing and to establish a conflict management concept (define operational framework).

The function strategic supply network modeling provides a methodology for the identification (identify strategic supply network), evaluation (evaluate strategic supply network) and selection (select strategic supply network) of potential suppliers, not only located in tier-1 but also in the subsequent tiers. Using evaluation criteria such as lowest cost, shortest delivery time or best quality, and corresponding evaluation methods, the identified supply networks are evaluated. If there is a positive result on the evaluation, the supply network is selected and contractually linked to the company.

Within the function strategic supply network qualification, the quality of a performing supplier network is evaluated using evaluation criteria and evaluation methods (evaluate quality of supply network). Dependent on the result of the evaluation, sanctions may be used to improve the quality of the supply network (improve quality of supply network).

In this article we focus on the modeling of strategic supply networks and specifically on the identification sub-task. The reason for it is that compared to the traditional strategic purchasing the supplier selection process undergoes the most evident changes in the shift to a supply network perspective. The expansion of the traditional frame of reference in strategic sourcing requires more information than merely data on existing and potential suppliers in tier-1. Instead, the supply networks connected with those suppliers have to be identified and evaluated, e.g., by comparing alternative supply networks. Since the identification of strategic supply networks builds the basis for the evaluation and selection, we introduce shortly the preliminary work done in the area of identification and modeling of strategic supply networks [27, 29, 34].

To model and visualize the network in a structured way, a specific strategic demand for a product to be manufactured is communicated from the OEM to existing and/or potential suppliers. Fig. 2 illustrates an example for an identification process and its results. In the example the OEM is connected to a potential network of suppliers as shown in the left part of Fig. 2. It is assumed that the OEM needs to order two products externally, product 1 and product 2 . During the identification process the OEM sends out demands for these products to its strategic suppliers in tier-1. In the example it is assumed that supplier 1-1 and supplier 1-2 get the demand for product 1 while supplier 1-3, supplier 1-4 and supplier 1-5 receive the demand for product 2 . These suppliers check whether they can fulfill the demand internally and, if not, send out subsequent demands to their respective suppliers. Each node executes the same process as described until the demand has reached the last tier. The requested information is then returned to the OEM, aggregated and finally visualized as a supply network, in which each participant of the supply network constitutes a network node. 


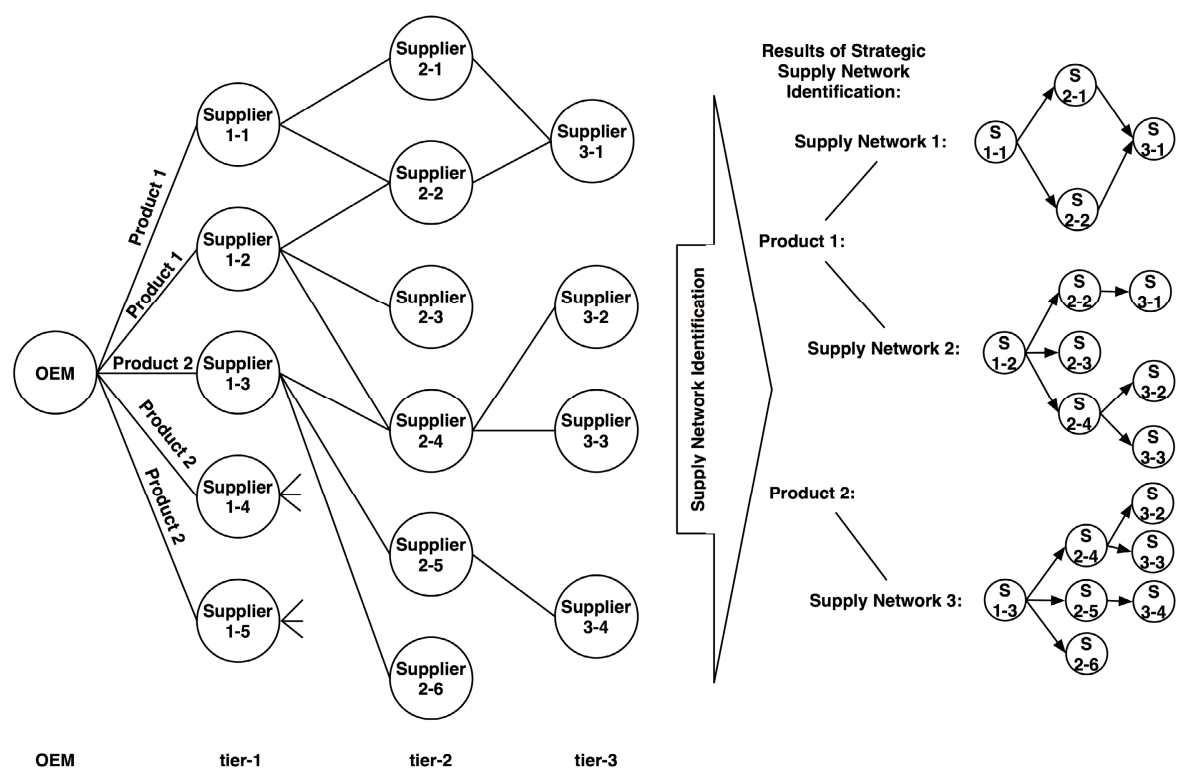

Fig. 2. Example for result of identification process

This process may result in the identification of several possible supply networks as shown in the right part of Fig. 2, where e.g. product 1 can be provided by two supply networks, supply network 1 (root node S1-1) and supply network 2 (root node S1-2), whereas product 2 can only be provided by supply network 3 . It is now up to the OEM to decide which of the potential strategic supply networks (in the example above for product 1) will be selected to fulfill its original demand. Therefore an evaluation process is necessary which has been introduced by the authors in [35]; it will not be elaborated in detail in this article.

\section{Enterprise Ontology and Its Application to the SSND Case}

As motivated in the introduction, we apply enterprise ontology for modeling the business domain. The specific methodology that is used for constructing the ontology of an enterprise is DEMO (Design \& Engineering Methodology for Organizations) [20, $21,36,37]$. As is explained in [21, 36, 37] a distinction is made between production acts and facts and coordination acts and facts. The transaction axiom aggregates these acts/facts into the standard pattern of the (business) transaction. Consequently, two worlds are distinguished: the production world (P-world) and the coordination world (C-world). The complete ontological model of an organization in DEMO consists of four aspect models (Fig. 3).

The Construction Model (CM) specifies the composition, the environment and the structure of the organization. It contains the identified transaction types and the associated actor roles and describes the links to production or coordination banks, where all production and coordination facts are stored. The Process Model (PM) details each 
single transaction type of the CM according to the universal transaction pattern [21]. In addition, the causal and conditional relationships between transactions are exhibited. The Action Model (AM) specifies the action rules that serve as guidelines for the actors in dealing with their agenda. It contains one or more action rules for every agendum type. The State Model (SM) specifies the object classes, fact types and ontological coexistence rules in the production world.

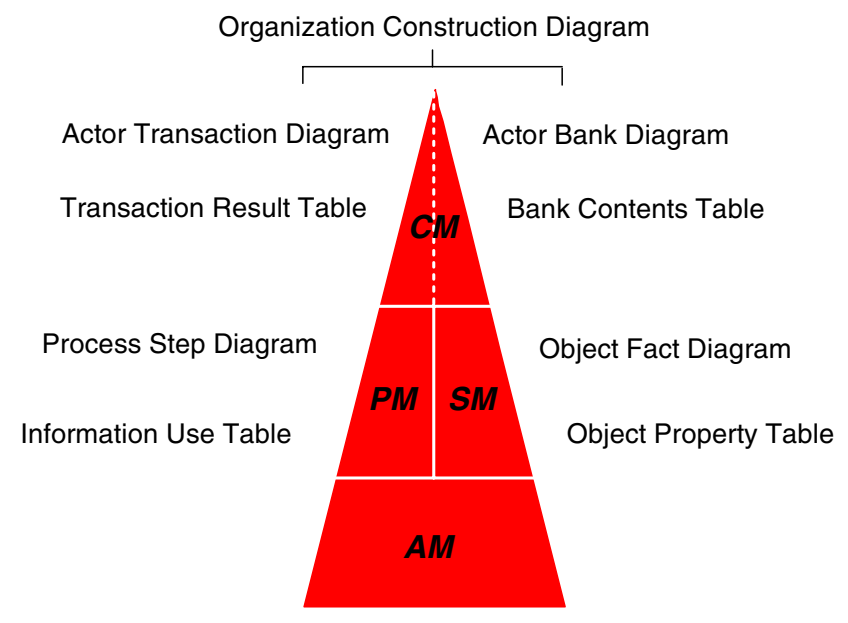

Action Rule Specifications

Fig. 3. The four aspect models

In Fig. 3 the CM triangle is split by a dashed line in a left and a right part. This is due to the logical sequence of producing the aspect models. First, the left part of the $\mathrm{CM}$ can be made straight away after having applied the elicitation procedure as discussed in [38]. It contains the active influences among actor roles, being initiator or executor of a transaction type. The CM is expressed in an Actor Transaction Diagram and a Transaction Result Table. Next, the Process Step Diagram, which represents a part of the PM, is produced and after that the AM, which contains the Action Rule Specifications. The action rules are expressed in a pseudo-algorithmic language, by which an optimal balance between readability and preciseness is achieved. Then the SM is produced, expressed in an Object Fact Diagram and an Object Property Table. Next, the right part of the CM is produced. It consists of an Actor Bank Diagram and a Bank Contents Table. Usually the Actor Bank Diagram is drawn as an extension of the Actor Transaction Diagram. Together they constitute the Organization Construction Diagram. After that we are able to complete the PM with the Information Use Table, showing which information is used in which process steps.

Based on this method, the ontology for the SSND case has been constructed. Space limitations prohibit us to provide a more extensive account of how the models in the figures below are developed. Also, we will not present and discuss the action rules. Fig. 4 exhibits the Organization Construction Diagram. The corresponding Transaction Result Table is shown in Table 1. 


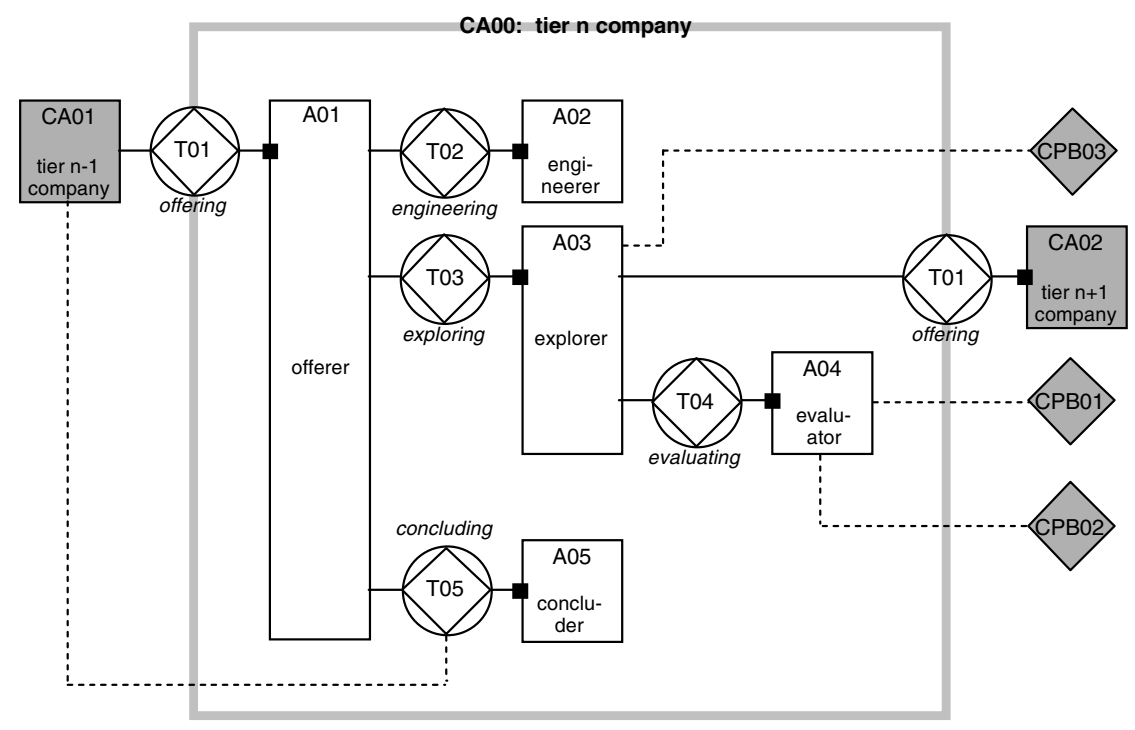

Fig. 4. Organization Construction Diagram of the SSND case

Table 1. Transaction Result Table of the SSND case

\begin{tabular}{|l|l|}
\hline transaction type & resulting P-event type \\
\hline T01 offering & PE01 supply contract $\mathrm{C}$ is offered \\
\hline T02 engineering & PE02 the BoM of assembly A is determined \\
\hline T03 exploring & PE03 supply contract $\mathrm{C}$ is a potential contract \\
\hline T04 evaluating & PE04 supply contract $\mathrm{C}$ is evaluated \\
\hline T05 concluding & PE05 supply contract $\mathrm{C}$ is concluded \\
\hline
\end{tabular}

The top or starting transaction type is the offering transaction T01. Instances of T01 are initiated by the environmental actor role CA01, which is a company in tier n-1 and executed by actor role A01 (offerer). This company asks the direct supplier (company in tier-n) for an offer regarding the supply of a particular product P. In order to make such an offer, A01 first initiates an engineering transaction T02, in order to get the bill of material of the requested product $\mathrm{P}$. This is a list of (first-level) components of $\mathrm{P}$, produced by A02 (engineerer). Next, A01 asks A03 (explorer) for every such component to get offers from companies that are able to supply the component. So, a number of exploring transactions T03 may be carried out within one T01, namely as many as there are components of $\mathrm{P}$ that are not produced by the tier-n company.

In order to execute each of these transactions, A03 has to ask companies for an offer regarding the supply of a component of $\mathrm{P}$. Since this is identical to the starting transaction T01, we model this also as initiating a T01. Now however, the executor of the T01 is a company in tier $(n+1)$. Consequently, the model that is shown in Fig. 4 must be understood as to be repeated recursively for every tier until the products to be supplied are elementary, i.e. non-decomposable. Note that, because of the being recursive, an offer (the result of a T01) comprises the complete bill of material of the concerned component of $\mathrm{P}$. 
Every offer from the companies in tier $\mathrm{n}+1$ is evaluated in a $\mathrm{T} 04$ transaction by the actor role A04 (evaluator). So, there is a T04 for every 'output' T01, whereby each company can use their own evaluation and decision rules. The result of a T04 is a graded offer for some component of $\mathrm{P}$. So, what A03 delivers back to A01 is a set of graded offers for every component of P. Next, A01 asks A05 (concluder), for every component of $\mathrm{P}$, to select the best offer. The result is a set of concluded offers, one for every component of P. This set is delivered to A01. Lastly, A01 delivers a contract offer for supplying $\mathrm{P}$, together with the set of concluded offers for delivering the components of $\mathrm{P}$. Because of the recursive character of the whole model, this offer includes the complete bill of material of $\mathrm{P}$, regardless its depth.

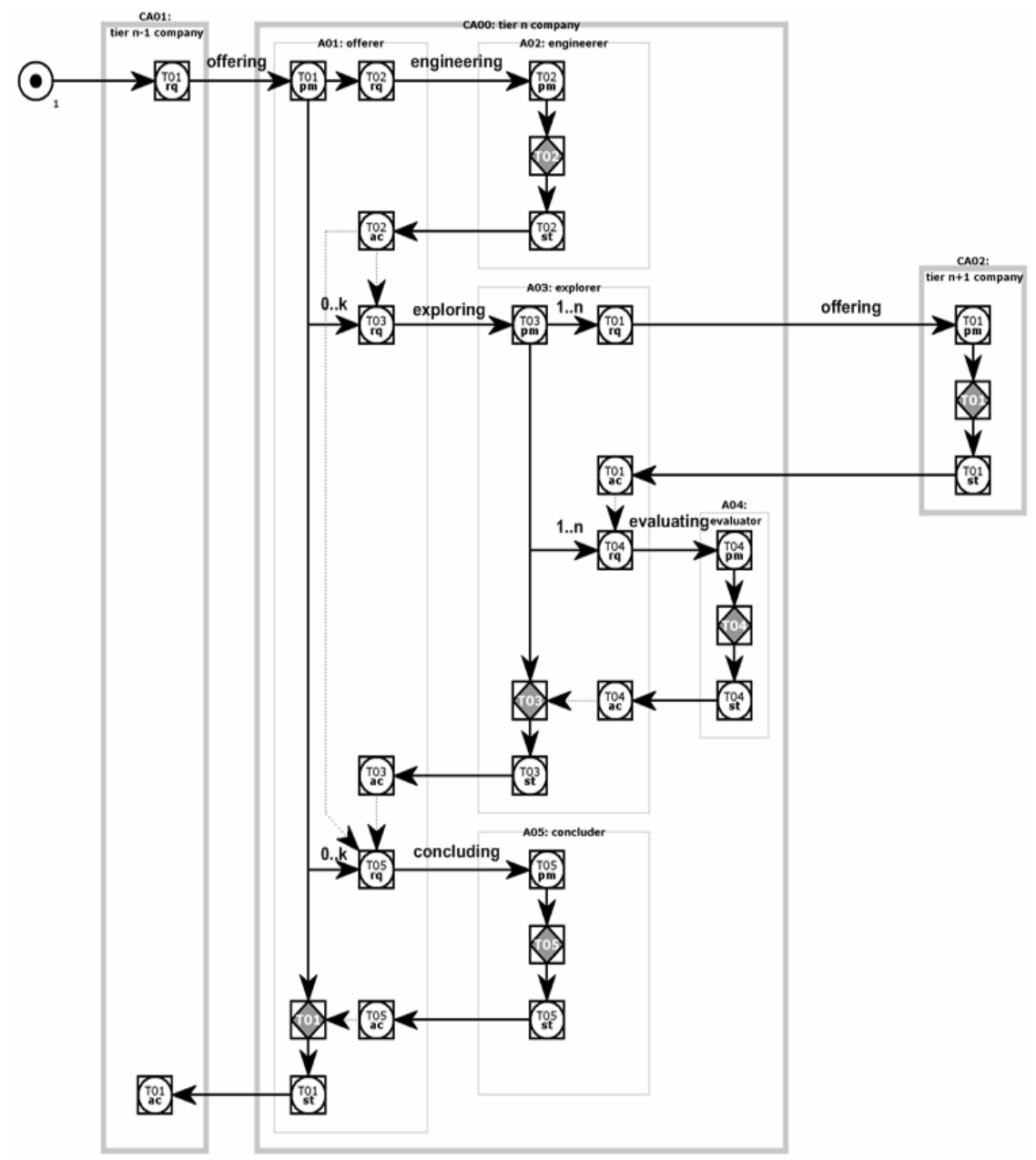

Fig. 5. Process Step Diagram of the SSND case 
Table 2. Assignment of process steps to shortcuts

\begin{tabular}{|l|l|l|l|l|}
\hline process steps names & shortcuts & & process steps names & Shortcuts \\
\hline request offering & T01/rq & & state exploration & T03/st \\
\hline promise offering & T01/pm & & accept exploration & T03/ac \\
\hline produce contract offering & T01/ex & & request evaluation & T04/rq \\
\hline state offering & T01/st & & promise evaluation & T04/pm \\
\hline accept offering & T01/ac & & produce contract evaluation & T04/ex \\
\hline request engineering & T02/rq & & state evaluation & T04/st \\
\hline promise engineering & T02/pm & & accept evaluation & T04/ac \\
\hline produce BoM explosion & T02/ex & & request conclusion & T05/rq \\
\hline state engineering & T02/st & & promise conclusion & T05/pm \\
\hline accept engineering & T02/ac & & produce concluded contract & T05/ex \\
\hline request exploration & T03/rq & & state conclusion & T05/st \\
\hline promise exploration & T03/pm & & accept conclusion & T05/ac \\
\hline produce potential contract & T03/ex & & & \\
\hline
\end{tabular}

The Organization Construction Diagram in Fig. 4 contains three external production banks. Bank CPB01 contains the data about a company that are relevant for the evaluation of offers. Bank CPB02 contains the different evaluation methods that can be applied. In every instance of T04, one of these methods is applied. CPB03 contains identifiers of all companies that may be addressed for an offer. Lastly, in the transaction result table (Table 1), the supply of a product by a (supplying) company to a (customer) company is called a contract.

Fig. 5 exhibits the process step diagram of the SSDN case. Due to visualization reasons only shortcuts are listed for the single process steps. For real names see Table 2. The process step diagram is based on the universal transaction pattern [37]. It shows how the distinct transaction types are related. For the SSND example case, only the so-called basic pattern (request, promise, execute, state, accept) has been used.

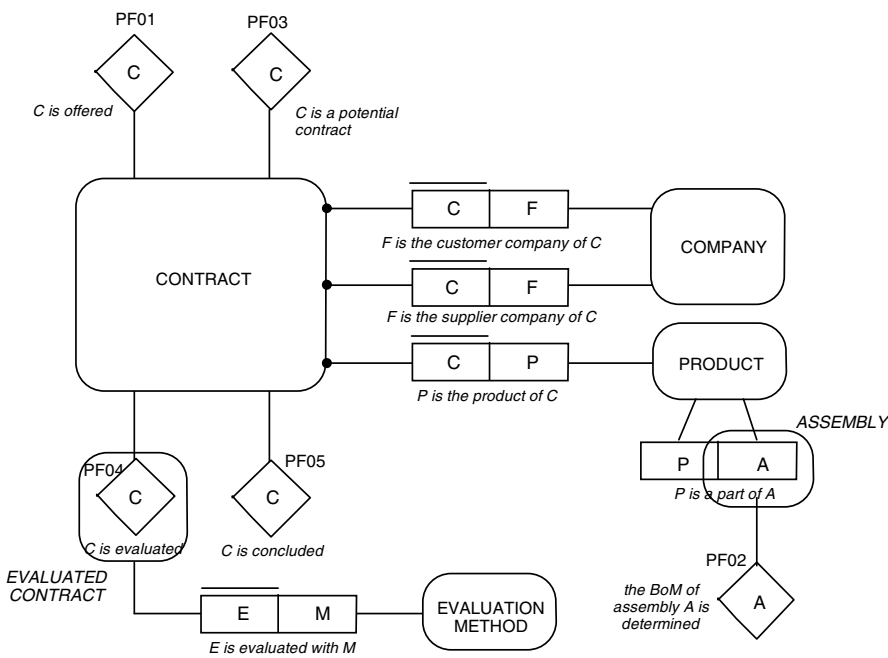

Fig. 6. Object Fact Diagram of the SSND case 
Table 3. Object Property Table of the SSND

\begin{tabular}{|l|l|l|}
\hline property type & object class & scale \\
\hline < company information $>$ & COMPANY & $<$ aggregated data $>$ \\
\hline < contract terms $>$ & CONTRACT & $<$ aggregated data $>$ \\
\hline sub_products $\left(^{*}\right)$ & PRODUCT & set of PRODUCT \\
\hline \#sub_products $(*)$ & PRODUCT & NUMBER \\
\hline suppliers $(*)$ & CONTRACT $*$ PRODUCT & set of COMPANY \\
\hline sub_contracts $(*)$ & CONTRACT & set of CONTRACT \\
\hline evaluation_mark & CONTRACT & NUMBER \\
\hline evaluation_marks $(*)$ & CONTRACT & set of NUMBER \\
\hline
\end{tabular}

From the state T01/pm (promised) a number of transactions T03 (possibly none) and a number of transactions T05 (possibly none) are initiated, namely for every firstlevel component of a product. This is expressed by the cardinality range $0 . . \mathrm{k}$. Likewise, from the state T03/pm, a number of transactions T01 and a number of transactions T04 are initiated, namely for every offer or contract regarding a firstlevel component of a product. The dashed arrows, from an accept state (e.g. T02/ac) to some other transaction state, represent waiting conditions. So, for example, the performance of a T03/rq has to wait for the being performed of the T02/ac.

Fig. 6 exhibits the Object Fact Diagram and Table 3 the Object Property Table. Together they constitute the State Model of the example case.

The Object Fact Diagram is a variant of the Object Role Modeling (ORM) model [39]. One of the major differences is that the OFD contains diamond-shaped unary fact types for representing the results of transactions, i.e., the production fact types. They correspond with the transaction results in Table 1. A roundangle around a fact type or a role defines a concept in an extensional way, i.e. by specifying the object class that is its extension. For example, the roundangle around the production fact type " $\mathrm{C}$ is evaluated" defines the concept of evaluated contract. Lastly, the roundangle around the role "A" of the fact type "P is a part of A" defines all assemblies, i.e. all products that do have parts. Properties are binary fact types that happen to be pure mathematical functions, of which the range is set of, usually ordered, values, called a scale. Instead of including them in an Object Fact Diagram they can be more conveniently represented in an Object Property Table. The property types marked by "(*)" in the Object Property Table are derived fact types. The derivation rules are as follows:

sub_products $(\mathrm{P})$ \#sub_products $(\mathrm{P})$ suppliers(F,P)

sub_contracts $(\mathrm{C})$

evaluation_marks (C)
$=\{\mathrm{X} \mid \mathrm{X} \in \mathrm{PRODUCT}$ and $\mathrm{X}$ is a part of $\mathrm{P}\}$;

$=\underline{\text { card }}($ sub_products $(\mathrm{P}))$;

$=\{\mathrm{X} \mid \mathrm{X} \in \mathrm{COMPANY}$ and $(\exists \mathrm{Y} \in \mathrm{CONTRACT}: \mathrm{P}$ is the product of $\mathrm{Y}$ and $\mathrm{X}$ is the supplying company of $\mathrm{Y}$ and $\mathrm{F}$ is the customer company of $\mathrm{Y})\}$;

$=\{\mathrm{X} \mid \mathrm{X} \in \mathrm{CONTRACT}$ and the product of $\mathrm{X}$ is $\mathrm{Z}$ and the product of $\mathrm{C}$ is $\mathrm{Y}$ and $\mathrm{Z}$ is a part of $\mathrm{Y}\}$; $=\{\mathrm{X} \mid \mathrm{X}$ is an evaluation mark of $\mathrm{C}\}$;

The information items as defined in the SM, including the derived fact types, constitute all information that is needed to develop a supply network for a particular product. 


\section{Identification of Business Components in the SSND Case}

The set of ontological models of an enterprise, as discussed above, constitutes the basis for the identification of business components. A business component provides a set of services out of a given business domain through well-defined interfaces and hides its implementation [40]. The specification of a business component is defined as a "complete, unequivocal and precise description of its external view" [41]. The enterprise ontology, satisfying the quality criteria (introduced in section 1) of providing a complete domain model, being described at the right granularity or level of detail and modeling only the essential business actions provides the necessary basis for the realization of business components. The enterprise ontology for the SSND case contains all essential information for that business domain.

The business components identification (BCI) method [24-26] applied in this section aims at grouping business tasks and their corresponding information objects into business components satisfying defined metrics. The metrics used - being loosely coupling and tight cohesion - are the basic metrics for the component-based development of inter-enterprise business applications focusing on the deployment of components that can be used in different enterprise systems [42-44]. According to the classification of business components identification methods by [44], the BCI method combines Clustering Analysis and CRUD (Create, Read, Update, Delete) based methods. With the BCI method we satisfy the recommendation of Wang et al. of combining current component identification methods in order to achieve satisfactory results.

Since the identification of business components is strongly dependant on the underlying business model, the BCI method uses the object classes and fact types from the State Model and the process steps from the Process Model, including their relationships. One can distinguish between three types of relationships necessary for the identification of business components. The relationship between single process steps, the relationship between information objects and the relationship between process steps and information objects. A relationship type distinguishes between subtypes expressing the significance of a relationship. E.g. the relationship between single process steps expresses - based on their cardinality constraints - how often a process step is executed within a transaction and therefore how close two process steps are related to each other in that business domain. The relationship between information objects defines how loosely or tightly the information objects are coupled, and the relationship between process steps and information objects defines whether a corresponding information object is used, created or altered while executing the respective process step. All types of relationship are of great relevance in order to define which information object and process steps belong to which component.

The relationships are modeled in the BCI method using a weighted graph. As the nodes represent information objects and process steps, the edges characterize the relationships between the nodes. Weights are used to define the different types and subtypes of relationships and build the basis for assigning nodes and information objects to components. Due to display reasons the graph is visualized in a three-dimensional representation having the process steps and information objects arranged in circles, and without showing the corresponding weights (see Fig. 7). 


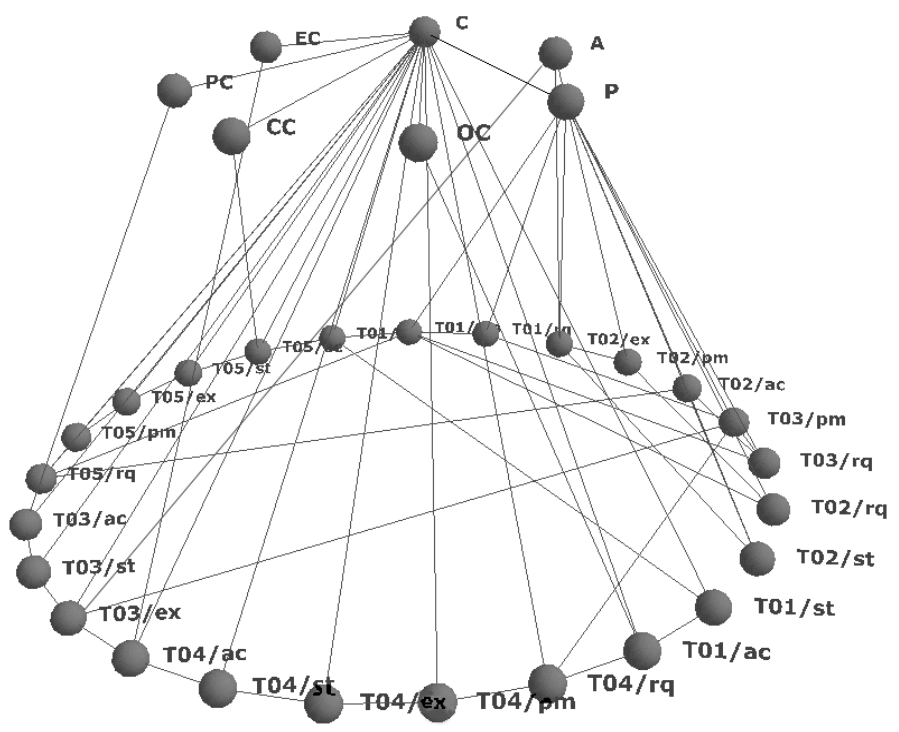

Fig. 7. Relationships between process steps and information objects

The graph shows all process steps and information objects as well as the relationships between them. For the purpose of clarity, only the shortcuts of all nodes are shown. For the real names, please see Table 2 and Table 4.

Table 4. Assignment of information object names to shortcuts

\begin{tabular}{|l|l|}
\hline information object name & shortcut \\
\hline Product & $\mathrm{P}$ \\
\hline Assembly & $\mathrm{A}$ \\
\hline Contract & $\mathrm{C}$ \\
\hline Evaluated Contract & $\mathrm{EC}$ \\
\hline Potential Contract & $\mathrm{PC}$ \\
\hline Concluded Contract & $\mathrm{CC}$ \\
\hline Offered contract & OC \\
\hline
\end{tabular}

In order to ensure optimal grouping satisfying the defined metrics of loosely coupling and tight cohesion, an optimization problem needs to be solved for which a genetic algorithm has been developed. The algorithm starts with a predefined solution (specific assignment of process steps and information objects to components) and generates better solutions through iterations. The starting solution is generated using a greedy graph-partitioning algorithm [45]. Using a model that provides a complete description of the relevant business domain implicates that a better starting solution is generated. The quality of the starting solution determines the quality of the resulting business components. The enterprise ontology provides an adequate basis for gaining all relevant information for building an adequate starting solution. 
For improving the starting solution, the Kernighan and Lin graph-partitioning algorithm [46] has been applied. This algorithm calculates the internal and external costs of the defined partitions and minimizes the external costs, representing minimal communication between components, by exchanging nodes between different graph partitions. Internal costs are defined as the sum of all weights of edges within a component, while external costs are defined as the sum of all weights of edges connecting nodes located in different partitions, and therefore in different components. Using this algorithm business component models have been generated for different business domains, starting from modeling small business domains, e.g. the one of strategic supply network development as presented in this article, to a business domain in the area of Customer Relationship Management (CRM) and Supply Chain Management (SCM) with more then 500 information objects and 1000 business tasks [47, 48]. In the following we describe how the information of the enterprise ontology is used to build the weighted graph that constitutes the basis for identifying business components, based on the optimization algorithm just explained.

The relationship between process steps is provided by the order in which they are executed (visualized by a link between two process steps). For the identification of business components we distinguish between standard, optional and main links, defining the significance of the relationships between two process steps. This is expressed in Fig. 5 by the cardinality constraints assigned to the links. If a link has the cardinality range $0 . .1$ we call it an optional link, since the following process step does not need to be executed. If the cardinality range is set to $0 . . n$ then we speak from a main link, indicating that the following process step is executed at least once. If no cardinality range is assigned to a link, we call it a standard link having the following process step executed exactly once. The different types of links are modeled by different weights in the graph. The process steps and their relationships are shown in Fig. 8, positioning all process steps as nodes in a circle and inserting edges for the relationship between two business services.

Let us have a closer look at the information objects relevant for the information system to be built. Fig. 6 and Table 3 introduce different types of potential information objects, namely the object classes, fact types and property types. Object classes

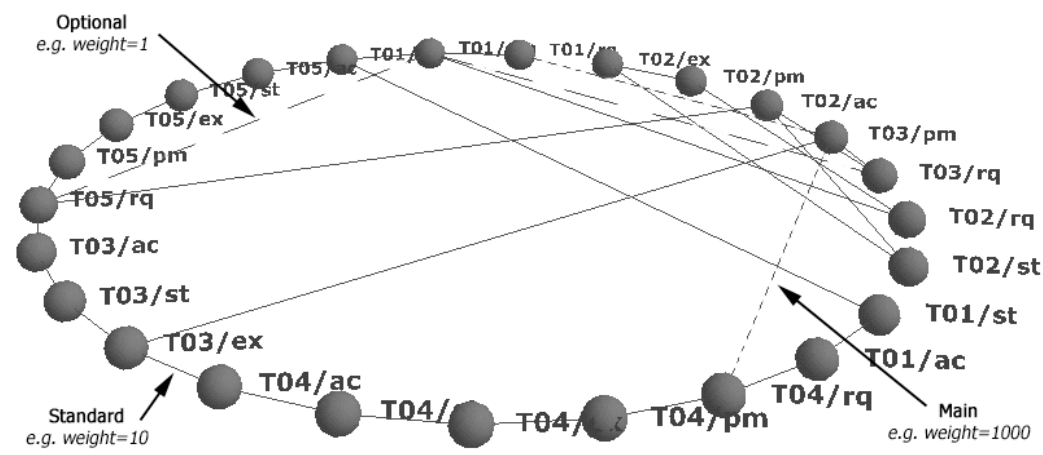

Fig. 8. Relationship between process steps 
that are provided by external information systems, are traded in a special way in BCI method. They concern the data that are contained in the external production banks (see Fig. 4). Due to space limitations we omit this kind of information here. The remaining information objects relevant for the component identification of the SSND case and their relationships are shown in Fig. 9. Regarding the different types of relationships between single information objects we distinguish between part-of, state-of and related-to expressed by means of edge weights. In the example case a 'Contract' (C) that has been evaluated is a state-of 'Contract' (C). Additionally, we have 'Product' $(\mathrm{P})$ being part-of 'Assembly' (A), whereas 'Contract' $(\mathrm{C})$ is related-to a specific 'Product' (P).

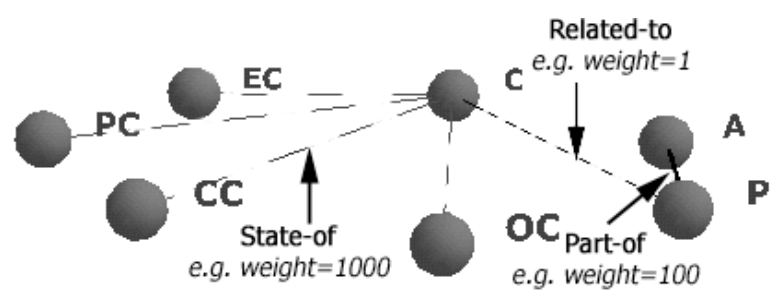

Fig. 9. Relationship between information objects

Next, the relationships between information objects and business services are examined. The information to define those relationships can be gained from the Create/Use Table, see Table 5, which is an extension of the Information Use table of the enterprise ontology.

Table 5. Create/Use Table of the SSND case

\begin{tabular}{|l|l|}
\hline object class or fact type & process steps \\
\hline PRODUCT & T01/rq T01/pm T02/ex T02/rq T02/pm T02/st \\
& T02/ac T03/rq T03/pm \\
\hline product P is a part of product A & T02/ac \\
\hline the BoM of assembly A is determined & T02/ac \\
\hline ASSEMBLY & T02/ex T03/ex \\
\hline CONTRACT & T01/ex T01/st T01/ac T03/ex T03/st T03/ac T04/ex \\
& T04/rq T04/pm T04/st T04/ac T05/ex T05/rq \\
& T05/pm T05/st T05/ac \\
\hline supply contract $C$ is offered & T01/ac \\
\hline supply contract $C$ is a potential contract & T03/ac \\
\hline supply contract $C$ is evaluated with method $M$ & T04/ac \\
\hline supply contract $C$ is concluded & T05/ac \\
\hline
\end{tabular}

It contains object classes and fact types that are assigned to specific process steps by differentiating objects that are used and objects that are created. The process steps in which an instance of an object class or property type is created are printed in italic, as are the production fact types (transaction results). For the SSND example, the relationships between information objects and process steps and their weights are visualized in Fig. 10. 


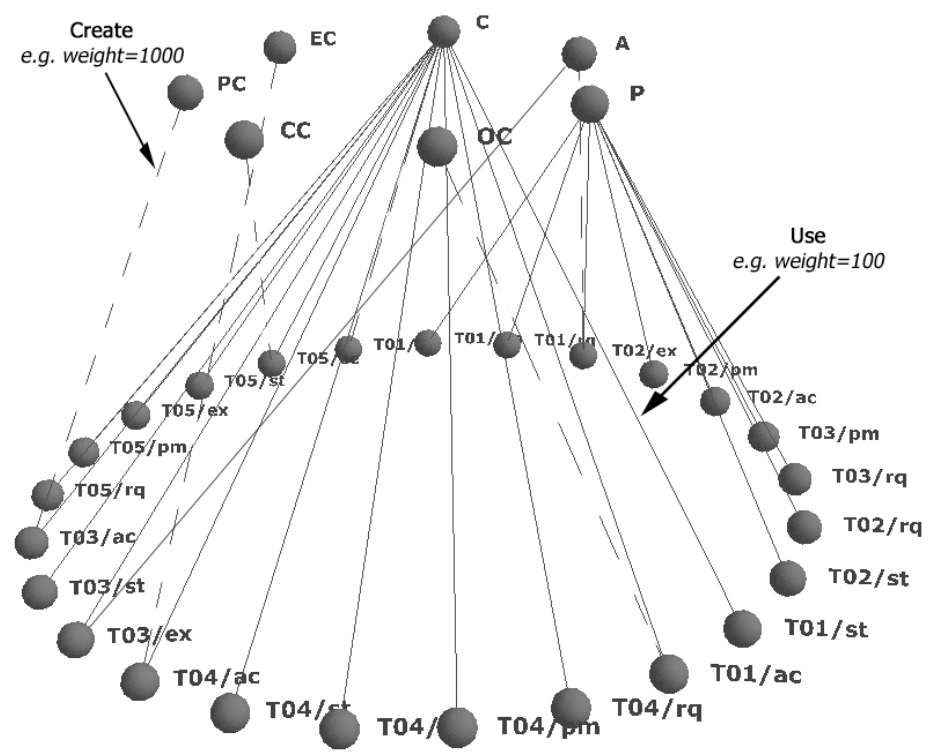

Fig. 10. Relationship between process steps and information objects

Combining the three dimensions of node dependencies - between information objects, between business services and between information objects and business services (shown in Fig. 8, Fig. 9 and Fig. 10) - results in the three dimensional model as shown in Fig. 7. This model is the basis for applying the genetic algorithms in order to cluster related nodes within single components. Applying the BCI method to that graph results in the following graph clustering (see Fig. 11).

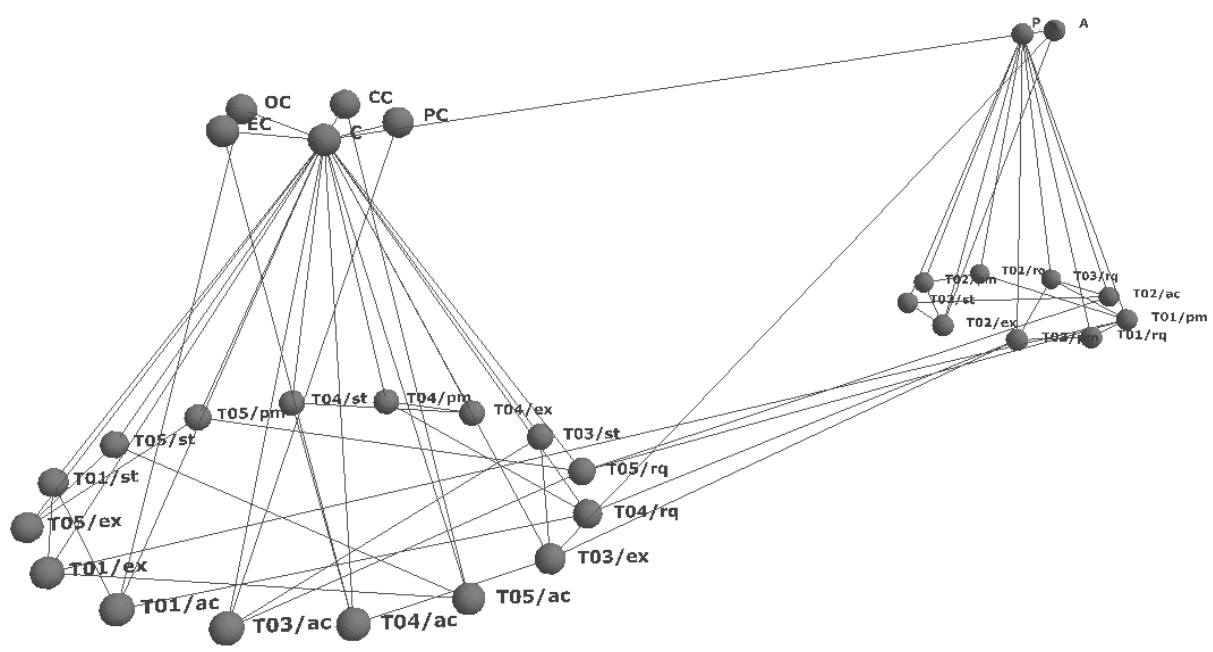

Fig. 11. Identified business components 
Now that all the nodes in the pictures are ordered and grouped as resulting from the optimization algorithm, two business components can be identified immediately: one containing the business tasks and information objects related to product management and one containing the business tasks and information objects related to contract management. The two components are therefore named Product Manager and Contract Manager and are shown in Fig. 12 according to the UML 2.0 notation [19].

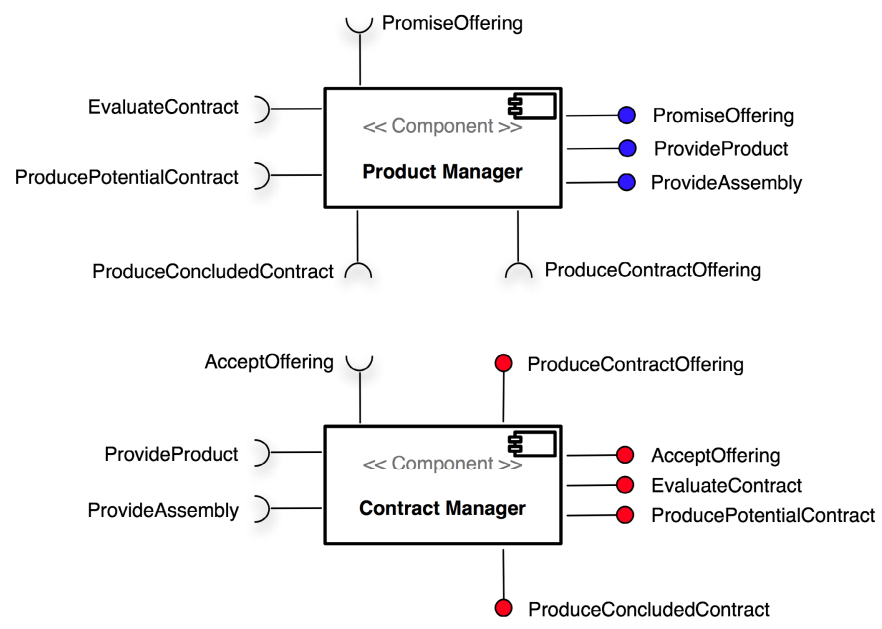

Fig. 12. Identified business components with their provided and required services

It is evident that the derivation of the components is strongly dependent on the weights chosen. Different results could be achieved in assigning different weights to the edges in the graph. In applying the BCI method to many real world cases, we aim at deriving reference values for the different weights.

Since the identified business components provide business services to or require business services from other business components either within an enterprise or between enterprises, the single business component services need to be defined. These services are related to the process steps executed in a business transaction. From the diagram in Fig. 5 - describing the process steps of the transaction types introduced in Fig. 4 - the business services are gained and modeled in Fig. 12 either as required services (composed of a semicircle attached to the related component by a line) or as provided services (composed of a circle attached to the component by a line).

Even if for this small example only two business components were found, the derivation of the services and information objects assigned to the components would not have been possible without a detailed analysis and modeling of the business domain. This information is essential and provides the basis for the implementation of the business components. Place limitations prevented us to derive components from a larger example domain. 


\section{Conclusions}

In this article, we have addressed the impact of using an enterprise ontology for identifying business components, defined as the highest level software components, directly supporting business activities. Although component-based software development may be superior to more traditional approaches, it leaves the problem of requirements engineering unsolved. Put differently, the component-based approach provides no criteria for determining that a set of identified components is complete (no component is missing) and minimal (there are no unnecessary components). Next to that, it provides no means for determining the point of departure, i.e. an appropriate model of the business domain.

The method presented and demonstrated in this article does solve these problems. First, the enterprise ontology constructed by means of DEMO is an appropriate model of the business domain. It satisfies the quality criteria as proposed in the introduction. As a consequence, the identified business components do really and directly support the business activities in which original new facts are created. Moreover, since the process steps (cf. Fig. 5) are atomic from the business point of view, one can be sure to have found the finest level of granularity that has to be taken into account. Also, one can be sure that this set of process steps is complete and minimal.

Second, the BCI method, based on the resulting models and tables of the enterprise ontology, provides an automated approach for the identification of business components satisfying defined metrics which are relevant for the development of reusable, marketable and self-contained business components. The metrics introduced in this article - being loosely coupling and tight cohesion - are the basic metrics for the component-based development of inter-enterprise business applications focusing on the deployment of components that can be on different enterprise systems.

The usability of the proposed enterprise ontology and the identification of business components is illustrated by means of a practical application of the domain of strategic supply network development. The approach seams to be very promising, but for the identification of the business components additional simulations with different weights and different optimization algorithms are necessary in order to make it applicable in practice.

\section{References}

1. Burtler, P., et al.: A Revolution in Interaction. The McKinsey Quarterly 1/97, 4-23 (1997)

2. Davenport, T.H.: The Future of Enterprise System-Enabled Organizations. Information Systems Frontiers 2(2), 163-180 (2000)

3. Davenport, T.H., Short, J.E.: The New Industrial Engineering: Information Technology and Business Process Redesign. Sloan Management Review 31(4), 11 (1990)

4. Malone, T.W., Lautbacher, R.J.: The Dawn of the E-Lance Economy. Harvard Business Review, 145-152 (September-October 1998)

5. Pine, B.J., Victor, B., Boynton, A.C.: Making Mass Customization Work. Havard Business Review 36(5), 108-119 (1993)

6. Tapscott, D., Ticoll, D., Lowy, A.: Digital Capital: Harnessing the Power of Business Webs, Boston (2000)

7. Kopanaki, E., et al.: The Impact of Inter-organizational Information Systems on the Flexibility of Organizations. In: Proceedings of the Sixth Americas Conference on Information Systems (AMCIS), Long Beach, CA (2000) 
8. Lambert, D.M., Cooper, M.C.: Issues in Supply Chain Management. Industrial Marketing Management 29(1), 65-83 (2000)

9. Barbier, F., Atkinson, C.: Business Components. In: Barbier, F. (ed.) Business Component-Based Software Engineering, pp. 1-26. Kluwer Academic Publishers Group, Dordrecht (2003)

10. Jang, Y.-J., Kim, E.-Y., Lee, K.-W.: Object-Oriented Component Identification Method Using the Affinity Analysis Technique. In: Konstantas, D., Léonard, M., Pigneur, Y., Patel, S. (eds.) OOIS 2003. LNCS, vol. 2817, pp. 317-321. Springer, Heidelberg (2003)

11. Levi, K., Arsanjani, A.: A Goal-driven Approach to Enterprise Component Identification and Specification. Communications of the ACM 45(10) (2002)

12. Réquilé-Romanczuk, A., et al.: Towards a Knowledge-Based Framework for COTS Component Identification. In: International Conference on Software Engineering (ICSE 2005), St. Louis, Missouri, USA. ACM Press, New York (2005)

13. Vitharana, P., Zahedi, F., Jain, H.: Design, Retrieval, and Assembly in Component-based Software Development. Communications of the ACM 46(11) (2003)

14. Dietz, J.L.G., Barjis, J.A.: Petri net expressions of DEMO process models as a rigid foundation for requirements engineering. In: 2nd International Conference on Enterprise Information Systems, Escola Superior de Tecnologia do Instituto Politécnico, Setúbal (2000); ISBN: 972-98050-1-6

15. Dietz, J.L.G.: Deriving Use Cases from Business Process Models. In: Song, I.-Y., Liddle, S.W., Ling, T.-W., Scheuermann, P. (eds.) ER 2003. LNCS, vol. 2813, pp. 131-143. Springer, Heidelberg (2003)

16. van der Aalst, W.M.P., van Hee, K.M.: Workflow Management: Models, Methods and Tools. MIT Press, MA (2001)

17. Jensen, K.: Coloured Petri Nets. Basic Concepts, Analysis Methods and Practical Use. Monographs in Theoretical Computer Science, Basic Concepts, vol. 1. Springer, Heidelberg (1997)

18. Scheer, A.-W.: ARIS - Business Process Modeling, 2nd edn. Springer, Berlin (1999)

19. UML, OMG Unified Modelling Language, Version 2.0. n.d, http://www.omg.org/technology/documents/modeling_spec_catalo g.htm\#UML

20. van Reijswoud, V.E., Mulder, J.B.F., Dietz, J.L.G.: Speech Act Based Business Process and Information Modeling with DEMO. Information Systems Journal (1999)

21. Dietz, J.L.G.: Enterprise Ontology - Theory and Methodology. Springer, Heidelberg (2006)

22. Dietz, J.L.G., Habing, N.: A meta Ontology for Organizations. In: Meersman, R., Tari, Z., Corsaro, A. (eds.) OTM-WS 2004. LNCS, vol. 3292, pp. 533-543. Springer, Heidelberg (2004)

23. Dietz, J.L.G.: The Deep Structure of Business Processes. Communications of the ACM 49(5) (2006)

24. Albani, A., Dietz, J.L.G., Zaha, J.M.: Identifying Business Components on the basis of an Enterprise Ontology. In: Interop-Esa 2005 - First International Conference on Interoperability of Enterprise Software and Applications, Geneva, Switzerland (2005)

25. Albani, A., Dietz, J.L.G.: The benefit of enterprise ontology in identifying business components. In: IFIP World Computing Conference. Santiago de Chile (2006)

26. Albani, A., et al.: Domain Based Identification and Modelling of Business Component Applications. In: Kalinichenko, L.A., Manthey, R., Thalheim, B., Wloka, U. (eds.) ADBIS 2003. LNCS, vol. 2798, pp. 30-45. Springer, Heidelberg (2003)

27. Albani, A., et al.: Dynamic Modelling of Strategic Supply Chains. In: Bauknecht, K., Tjoa, A.M., Quirchmayr, G. (eds.) EC-Web 2003. LNCS, vol. 2738, pp. 403-413. Springer, Heidelberg (2003)

28. Albani, A., Müssigmann, N., Zaha, J.M.: A Reference Model for Strategic Supply Network Development. In: Loos, P., Fettke, P. (eds.) Reference Modeling for Business Systems Analysis. Idea Group Inc. (2006) 
29. Albani, A., Winnewisser, C., Turowski, K.: Dynamic Modelling of Demand Driven Value Networks. In: Meersman, R., Tari, Z. (eds.) OTM 2004. LNCS, vol. 3290, pp. 408-421. Springer, Heidelberg (2004)

30. McIvor, R., Humphreys, P., McAleer, E.: The Evolution of the Purchasing Function. Journal of Strategic Change 6(3), 165-179 (1997)

31. Ammer, D.: Materials Management, 2nd edn. Homewood (1968)

32. Kaufmann, L.: Purchasing and Supply Management - A Conceptual Framework. In: Hahn, D., Kaufmann, L. (eds.) Handbuch Industrielles Beschaffungsmanagement, pp. 3-33. Wiesbaden (2002)

33. Carr, A.S., Pearson, J.N.: Strategically managed buyer - supplier relationships and performance outcomes. Journal of Operations Management 17, 497-519 (1999)

34. Albani, A., et al.: Component Framework for Strategic Supply Network Development. In: Benczúr, A.A., Demetrovics, J., Gottlob, G. (eds.) ADBIS 2004. LNCS, vol. 3255, pp. 6782. Springer, Heidelberg (2004)

35. Albani, A., Müssigmann, N.: Evaluation of Strategic Supply Networks. In: Meersman, R., Tari, Z., Herrero, P. (eds.) OTM-WS 2005. LNCS, vol. 3762, pp. 582-591. Springer, Heidelberg (2005)

36. Dietz, J.L.G.: The Atoms, Molecules and Fibers of Organizations. Data and Knowledge Engineering 47, 301-325 (2003)

37. Dietz, J.L.G.: Generic recurrent patterns in business processes. In: Mira, J., Álvarez, J.R. (eds.) IWANN 2003. LNCS, vol. 2687. Springer, Heidelberg (2003)

38. Dietz, J.L.G.: The notion of business process revisted. In: Meersman, R., Tari, Z. (eds.) OTM 2004. LNCS, vol. 3290, pp. 85-100. Springer, Heidelberg (2004)

39. Halpin, T.A.: Information Modeling and Relational Databases. Morgan Kaufmann, San Francisco (2001)

40. Fellner, K., Turowski, K.: Classification Framework for Business Components. In: Proceedings of the 33rd Annual Hawaii International Conference On System Sciences, Maui, Hawaii. IEEE, Los Alamitos (2000)

41. Ackermann, J., et al.: Standardized Specification of Business Components, Gesellschaft fÜr Informatik, Working Group 5.10.3, Technical Report, Augsburg (2002)

42. Jain, H., Chalimeda, N.: Business Component Identification - A Formal Approach. In: Proceedings of the Fifth International Enterprise Distributed Object Computing Conference (EDOC 2001). IEEE Computer Society, Los Alamitos (2001)

43. Kim, S.D., Chang, S.H.: A Systematic Method to Identify Software Components. In: 11th Asia-Pacific Software Engineering Conference (APSEC) (2004)

44. Wang, Z., Xu, X., Zhan, D.: A Survey of Business Component Identification Methods and Related Techniques. International Journal of Information Technology 2(4), 229-238 (2005)

45. Jungnickel, D.: The Greedy Algorithm. In: Jungnickel, D. (ed.) Graphs, Networks and Algorithms, pp. 123-146. Springer, Berlin (2005)

46. Kernighan, B.W., Lin, S.: An efficient heurisitc procedure for partitioning graphs. Bell Systems Technical Journal 49, 291-307 (1970)

47. Selk, B., Klöckner, K., Albani, A.: Enabling interoperability of networked enterprises through an integrative information system architecture for CRM and SCM. In: International Workshop on Enterprise and Networked Enterprises Interoperability (ENEI 2005), Nancy, France (2005)

48. Selk, B., et al.: Experience Report: Appropriateness of the BCI-Method for Identifying Business Components in large-scale Information Systems. In: Conference on ComponentOriented Enterprise Applications (COEA 2005) in conjunction with the Net.Objectdays, Erfurt, Germany (2005) 